\title{
DESMATAMENTO E EXPANSĀO HORIZONTAL DA AGRICULTURA NA BACIA DO RIO TOROPI, RS
}

Dirce Maria Suertegaray Rossato

Departamento de Geociēncias. Centro de Ciências Naturais e Exatas. UFSM. Santa Maria, RS.

RESUMO

Este trabalho apresenta dados sobre desmatamento e expan são horizontal da agricultura, calculados para a bacia do rio Toro pi-RS, a partir de mapas temáticos elaborados com base em fotografias aēreas. Os dados revelam um significativo decréscimo da vegetação na tural e reflorestamento e um aumento das āreas agrỉcolas. Nos doze anos estudados (1964 a 1975), a Mata Subtropical, os Capões, e as āreas com eucalipto tiveram suas äreas reduzidas, em valores relat vos, de $25,51 \%, 56,03 \%$ e $35,62 \%$ respectivamente, enquanto a ārea agrícola obteve um aumento de $73,75 \%$. 0 aumento das äreas de culti vo, analisadas por compartimento de relevo, foi maior nos comparti mentos à jusante (Depressão Central e Rebordo do Planalto) que, de 1964 a 1975 tiveram suas āreas agrícolas aumentadas em $82,38 \%$. A ārea agrícola do Planalto, obteve um aumento significativo, embora menor, correspondendo a $60,62 \%$.

\section{SUMMARY}

ROSSATO,D.M.S., 1980. Deforesting and agricultural horizontal expan sion in the Toropi River Basin, RS. Ciência e Natura (2): $77-90$.

This work presents data on deforesting and agriculturat ha rizontal expansion. The calculated data to the Toropi riverbasin was based on tematic maps that were made with basis on aireal pictures. The data show significant decrease of the natural yegetation and reforesting, with an increase of agricultural areas. In the twelve years that they were studied (1964 to 1975) the subtropical woods, the groves and the areas with eucaliptus had their areas reduced in relative values in $25.51 \%, 56.03 \%$ and $35,62 \%$, respectively, whereas the agricultural area had an increase of $73.75 \%$. The increase in the cultivated areas evaluated by relief compartment was larger in the downstream compartments (Central depression and plain edge), that from 1964 to 1975 had its agricultural areas increased by $82.38 \%$. The agricultural area of the plains has also increased, though in smaller scale, equivalent to $60.62 \%$. 


\section{INTRODUÇAO}

0 estudo sobre desmatamento e expansão horizontal da agri cultura na bacia do rio Toropi, se insere em trabalho mais amplo que vem sendo realizado nesta bacia. Não obstante, acredita-se de interes se divulgar alguns dados relativos ao indice de desmatamento e expan são das āreas de lavoura, encontrados, pela comparação das āreas ocu padas por essas diferentes categorias, nos anos de 1964 a 1975.

A importância dos estudos sobre grau de desmatamento se re veste de significado porque a vegetação, particularmente aquela de grande porte, constitui o sustentáculo do solo, evitando, desta for ma, a atuação direta dos agentes intempēricos e a consequente inten sificação dos processos de degradação. Em outras palavras, é a ve getação de grande porte o fator mais eficaz na minimização dos pro cessos geomorfológicos, devido ao seu efeito de interceptação que se resume "em defesa do terreno do impacto da chuva, efeito de retração no perỉodo de precipitação e retenção do volume apreciāvel de água nos diversos componentes do edificio vegetal" (1). Assim, "na mata a chuva se espalha pela cobertura das árvores, atingindo lenta e in diretamente 0 solo, que ainda é protegido pelas folhas caỉdas, gramī neas e pelos componentes orgānicos em decomposição" (2) impedindo, desta forma, a lavagem räpida do solo e conservando a umidade.

Por outro lado, retirada a vegetação, aumenta a eficácia dos processos de degradação, porque "a cobertura vegetal está subs tituīda por outra cujas propriedades geomorfológicas são muito dife rentes" (3) principalmente quando essa vegetação é substituīda por culturas, pois "as plantas cultivadas nunca alcançam a mesma densi dade que a vegetação natural"... (3), submetendo, desta forma, a ver tente a uma maior intensificação morfogenética, devido à maior efi ciēncia do bombardeio do solo pelas gotas de chuva.

Esta situação é evidenciada na bacia do rio Toropi, parti cularmente no setor constituído pelo Rebordo do Planalto. Neste, a vegetação original (Mata Subtropical) vem sofrendo um processo contî nuo de devastação, devido inicialmente à implantação de colōnias, cen trada na pequena propriedade. Posteriormente devido à transformação na agricultura da região, ocorrida particularmente após 1960 que exi giu dos colonos a expansão das āreas de cultivo, para obterem, desta forma, uma maior produção.

\section{CARACTERIZAÇAO DA AREA EM ESTUDO}

o rio Toropi constitui uma bacia afluente do rio Ibicuí, no Estado do Rio Grande do Sul. Apresenta ārea de aproximadamente $3.370,29 \mathrm{~km}^{2}$, e se localiza, mais precisamente, entre os meridianos de 
$53^{\circ} 40^{\prime}$ e $54^{\circ} 40^{\prime}$ Long. W e entre os paralelos de $29^{\circ}$ e $29^{\circ} 40^{\prime}$ Lat. Sul. Pela extensão e localização, essa bacia drena duas unidades morfolō gicas do Rio Grande do Sul: o Planalto e a Depressão Central. Figu ra 1 .

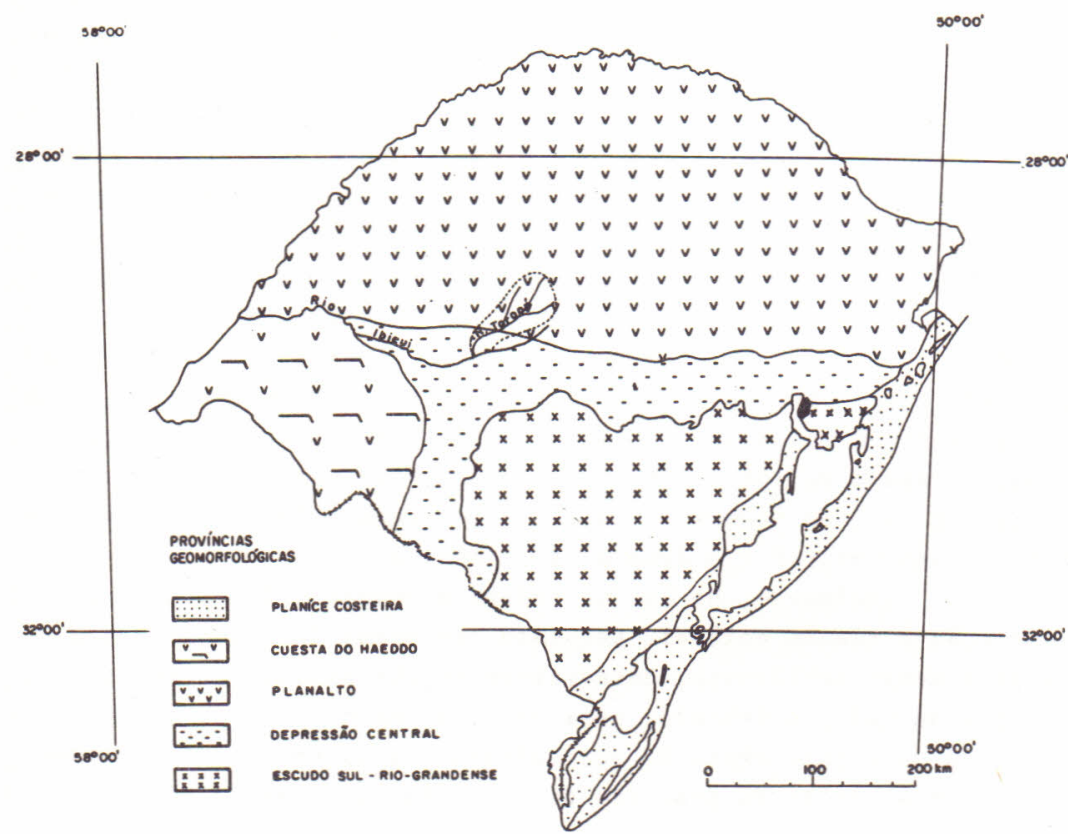

Figura 1. Localização geográfica da bacia do Rio Toropi no Estado do Rio Grande do Sul.

Litologicamente, dominam a bacia dois grupos de rochas:as vulcānicas e as sedimentares. Tanto as primeiras como as segundasdão origem a formas suaves, com declividades em torno de 5 a $10 \%$, com ex ceção do Rebordo do Planalto onde a inclinação das vertentes é mais acentuada, com declives em torno de 25 a $30 \%$. No que se refere ao so 10, dois grupos dominam na bacia. O primeiro engloba os solos que se desenvolvem a partir do arenito e que apresentam, embora as fracas de clividades ( 6 a $10 \%$ ), erosão, de moderada a forte. O segundo abran ge àqueles desenvolvidos a partir das rochas vulcânicas e,mesmo ocor rendo em āreas de moderadas declividades como é o caso do solo Guas supi, são considerados como altamente susceptiveis à erosão.

Quanto à vegetação, duas formações vegetais recobrem a ba cia: a vegetação de campo, que recobre as formas tỉpicas do planal to e da Depressão Central, entremeada de mata-galeria; e a vegetação 
arbörea (Mata Subtropical Subcaducifölia), originalmente desenvolvi da na porção denominada Rebordo do Planalto, onde a topografia é a mais acidentada de toda a bacia, e onde, segundo a caracterização dos solos, estes são os mais fortemente susceptíveis à erosão.

0 clima da bacia, segundo KÖPPEN ē do tipo CFa, com as chu vas bem distribuỉdas o ano todo e verões quentes. Não obstante, ana lisando os dados da estação de Jūlio de Castilhos (representativa do setor da bacia que drena o Planalto) e os dados da estação de Santa Maria (representativa da ārea que drena a Depressão Central e Rebor do do Planalto), constata-se uma compartimentação climätica, revela da pela diferenciação na mēdia tërmica e nos indices mëdios de pre cipitação para as duas estações. Assim, enquanto a primeira apresen ta mēdias térmicas anuais em torno de $19^{\circ} \mathrm{C}$, a segunda registra valo res em torno de $20,7^{\circ} \mathrm{C}$. 0 mesmo é observāvel para a precipitação, pois enquanto a precipitação média é de $1488,2 \mathrm{~mm}$ na estação meteo rolōgica de Júlio de Castilhos, em Santa Maria, as precipitações a tingem a média de $1622,7 \mathrm{~mm}$. Is to caracteriza uma compartimentação climātica que, em termos de umidade, favorece a faixa que constitui a Depressão Central e o Rebordo do Planalto.

Finalmente, no que se refere à ocupação do espaço, a dife renciação é tambēm notāvel. Enquanto nas āreas de campo, topografi camente menos declivosas, desenvolveu-se uma atividade centrada na criação de gado, o Rebordo, ārea originalmente de mata, caracteriza -se pelo desenvolvimento da agricultura, feita em pequenas proprie dades, originārias do processo de colonização europēia no Rio Gran de do Sul.

Em sintese, a bacia do rio Toropi apresenta características peculiares, onde o Rebordo do Planalto, dado à associação de diferen tes fatores como: maiores declividades, maior susceptibilidade do so 10 à erosão, maior umidade e elevado grau de desmatamento, constitui um compartimento com probabilidade de maior degradação.

MATERIAL E TECNICAS

0 material utilizado para a realização deste trabalho cons tou de fotografias aēreas (2 jogos: um de 1964 na escala de 1:60000 e outro de 1975, na escala de 1:110.000, cartas topogräficas da Dire toria do Serviço Geogrāfico do Exército na escala de 1:100.000 (Fó Ihas de General Vargas, Vila Clara, Rio Guassupỉ, São Pedro do Sul, Tupanciretã e Jari), além de estereoscōpios e Map-o-Graph, utiliza dos na elaboração de mapas temāticos e medidor de ārea folhar, para o cálculo de āreas de cobertura vegetal e āreas de uso do solo com cultivo. 
A tēcnica bäsica empregada foi a fotointerpretação para a identificação e delimitação das āreas de uso do solo e vegetação, na bacia do rio Joropi. Nesta tarefa foi utilizada a chave de identifi cação usada no trabalho sobre "O Uso da Terra e a Cobertura Vegetal do Rio Grande do Sul" (4). As categorias identificadas e delimitadas foram: āreas de cultivo (sem especificação do tipo), vegetação natu ral (Mata Subtropical e Capões) e reflorestamento (eucalipto).

Feito o levantamento do uso do solo, passou-se para a ela boração dos mapas temáticos. Primeiramente foi elaborado um mapa, na escala de 1:100.000, com base nas Cartas Topográficas da Diretoria do Serviço Geográfico do Exército. De posse deste mapa, em duas vias, foram lançadas as informações obtidas atravēs da fotointerpre tação, utilizando-se o aparelho Map-o-Graph, que permitiu a unifor mização das escalas para o posterior cālculo de āreas.

Com estes dois mapas, um para 1964 e outro para 1975, na escala de 1:100.000, passou-se à medição das áreas de cultivo, vege tação natural e reflorestamento. Para tanto, o procedimento adotado constituiu, num primeiro momento, da extração de todas as āreas de ve getação natural (nas diferentes categorias), de cultivo agrïcola e reflorestamento, agrupadas numa ūnica ārea, por categoria.Posterior mente, àreas foram recortadas e colocadas no aparelho denominado me didor de ārea folhar, que permite determinar a medida gráfica das äreas em $\mathrm{cm}^{2}$, sendo finalmente transformados para medidas reais, usan do-se a escala do mapa.

\section{RESULTADOS}

Conforme jä mencionamos, a cobertura vegetal original da bacia do rio Toropi, é representada pela vegetação de campo e de ma ta, predominando a primeira. Os valores encontrados, com base no ma pa de vegetação natural e uso do solo para agricultura de 1964 (Ane xo 1), foram de 19.216 ha de Mata Subtropical, 5.351 ha de Capões, 19.562 ha de āreas agrícolas, 1.303 ha de āreas de reflorestamento e os restantes 291.597 ha de campo. Isso corresponde, em valores rela tivos, a um total de $86,51 \%$ de āreas de campo, contra $7,28 \%$ de vege tação de mata (incluindo a Mata Subtropical e ārea de Capões), 5, $80 \%$ de āreas agrícolas e $0,38 \%$ de ārea utilizada com reflorestamento de eucalipto.

Comparando estes dados com os valores calculados sobre o mapa representativo do ano de 1975 (Anexo 2), observa-se uma diminui ção das āreas de vegetação de grande porte e reflorestamento, e um aumento significativo das āreas agrĩcolas (Tabela I). Para este ano temos em valores relativos, ārea coberta por Mata Subtropical corres 
pondendo a 4,24\% da ārea total, com um decrēscimo em relação a 1964 de $1,46 \%$; àrea de ocorrência de capões com $0,69 \%$ (decréscimo de $0,89 \%$ sobre a ārea de 1964) e reflorestamento com $0,24 \%$, o que corresponde também a um decréscimo de $0,14 \%$ em relação ao ano base. Jā o uso do solo para cultivo sofreu, neste periodo, um aumento na ārea passando de $5,80 \%$ da ārea total da bacia em 1964 , para $10,80 \%$ da ārea total em 1975

TABELA I. COMPARAÇAO DA OCUPAÇAO DO SOLO POR CATEGORIA DE USO NA BA CIA DO RIO TOROPI, RS ENTRE OS ANOS DE 1964 E 1975.

\begin{tabular}{lrrrrr}
\hline \multirow{2}{*}{$\begin{array}{c}\text { CATEGORIA } \\
\text { DE USO }\end{array}$} & \multicolumn{1}{c}{ Ha } & \multicolumn{1}{c}{$\%$} & \multicolumn{1}{c}{ Ha } & \multicolumn{1}{c}{$\%$} & \multicolumn{1}{c}{\begin{tabular}{c} 
VARIAÇAO \\
\cline { 2 - 5 }
\end{tabular}} \\
\hline Floresta & 19.216 & 5,70 & 14.315 & 4,24 & $-1,46$ \\
Subtropical & 5.351 & 1,58 & 2.353 & 0,69 & $-0,89$ \\
Capões & 19.562 & 5,80 & 33.989 & 10,08 & $+4,28$ \\
Area cultivada & 1.303 & 0,38 & 839 & 0,24 & $-0,14$ \\
Reflorestamento & 291.597 & 86,51 & 285.533 & 84,72 & $-1,79$ \\
Campo & 337.029 & $100 \%$ & 337.029 & $100 \%$ & - \\
\hline Total & & & & & \\
\hline
\end{tabular}

Considerando, por outro lado, o ano de 1964 como ano base (total das äreas equivalendo a 100\%) e calculando os percentuais de aumento e diminuição das diferentes categorias (Tabela II), ficou de monstrádo que de 1964 a 1975, houve diminuição nas āreas de Mata Sub tropical e Capões de $25,5 \%$ e $56,03 \%$, respectivamente. Quanto ao re florestamento, o percentual de diminuição foi de $35,52 \%$. A ārea cul tivada, no entanto, expandiu-se aumentando nesses doze anos $73,75 \%$ da ārea.

TABELA II. VARIAÇÃO PERCENTUAL NA OCUPAÇĂO DO SOLO POR CATEGORIA DE USO NA BACIA DO RIO TOROPI, RS.

\begin{tabular}{lccc}
\hline \multicolumn{1}{c}{ CATEGORIA } & OCUPAÇAO & $(\%)$ & VARIAÇAO \\
\multicolumn{1}{c}{ DE USO } & 1964 & 1975 & $\%$ \\
\hline Floresta & 100,00 & 74,49 & $-25,51$ \\
Subtropical & 100,00 & 43,97 & $-56,03$ \\
Capões & 100,00 & 173,75 & $+73,75$ \\
Area cultivada & 100,00 & 64,38 & $-35,62$ \\
Reflorestamento & & & \\
\hline
\end{tabular}

* O decréscimo relativo às áreas de reflorestamento, deve ser consi derado com reserva, porque as āreas ocupadas com esta categoria de uso do solo, são muito reduzidas e, sendo a escala das fotos dife rente, podem ter ficado sem mapear algumas āreas, que na escala das fotos de $1975(1: 110.000)$ se reduziram a pontos de difícil identifi cação 
Como o aumento das āreas agrỉcolas è significativo, o se gundo passo é verificar se as maiores āreas de lavoura localizam-se na zona originalmente de Mata Subtropical (Rebordo do Planalto)e De pressão Central ou na zona de Campos do Planalto. Para obtermos es tes valores, estabelecemos os percentuais das āreas desses comparti mentos (previamente delimitados), sobre o total da ārea agrícola da bacia. Os resultados indicaram tanto para 1964 como para 1975, um maior percentual de āreas de cultivo (Tabela III) na zona original mente de mata do Rebordo e Depressão Central. Para 1975, encontrou-se $63,32 \%$, da ārea agrícola localizada no Rebordo e Depressão Central contra $36,68 \%$ na região do planalto.

Este fato não ē de surprender na medida em que se sabe que os campos do planalto são utilizados predominantemente com pastagens e que, especificamente na zona originalmente de mata ē que predomi na a agricultura, desenvolvida por imigrantes alemães, italianos e seus descendentes.

TABELA III. USO AGRICOLA DO SOLO POR COMPARTIMENTO DE RELEVO NA BA CIA DO RIO TOROPI RS, NOS ANOS DE 1964 E 1975.

\begin{tabular}{|c|c|c|c|c|}
\hline \multirow{3}{*}{ COMPARTIMENTO } & \multicolumn{2}{|c|}{1964} & \multicolumn{2}{|r|}{1975} \\
\hline & \multicolumn{2}{|c|}{ USO AGRICOLA } & \multicolumn{2}{|c|}{ USO AGRICOLA } \\
\hline & $\mathrm{Ha}$ & $\%$ & $\mathrm{Ha}$ & $\%$ \\
\hline Planalto & 7.761 & 39,67 & 12.466 & 36,68 \\
\hline $\begin{array}{l}\text { Rebordo e } \\
\text { Depressão } \\
\text { Central }\end{array}$ & 11.801 & 60,33 & 21.523 & 63,32 \\
\hline Tota 1 & 19.562 & $100 \%$ & 33.989 & $100 \%$ \\
\hline
\end{tabular}

Esta anālise permite concluir sobre o predomīnio das āreas de cultivo nos compartimentos a jusante da bacia (Rebordo e Depres são Central). Entretanto, ē interessante demonstrar a situação, no que se refere ao aumento da ārea cultivada nestes doze anos, para ca da compartimento individualmente. Para isto, utilizou-se o mesmo pro cedimento expresso na Tabela II. Os resultados obtidos indicam ele vados valores relativos de aumento das āreas de cultivo, seja nas áreas de campo do planalto, seja nas āreas a jusante, representados por $60,82 \%$ e $82,38 \%$ respectivamente. (Tabela IV).

Estes dados demonstram a tendência à intensificação das á reas de cultivo, seja nas āreas originalmente agrícolas, seja nas äreas tradicionalmente pastoris, incrementada pelo aumento das āreas de cultivo nas pequenas unidades de produção bem como pela intens $\underline{i}$ ficação da produção de trigo e soja, em grandes lavouras. 
TABELA IV. AUMENTO PERCENTUAL DA ĀREA AGRICOLA, 1975 EM RELAÇÃO A 1964, POR COMPARTIMENTO DE RELEVO NA BACIA DO RIO TOROPI, RS.

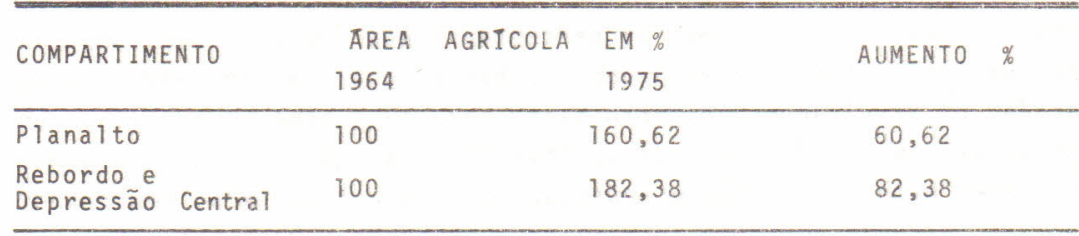

Finalmente, estabelecendo a mëdia para os doze anos, obtēm -se um indice de desmatamento de aproximadamente $2,12 \%$ ao ano, das āreas de Mata Subtropical e 4,6\% das äreas de Capões. Comparando es ses valores com o aumento das äreas cultivadas que foi de aproxima damente $6,07 \%$ durante esse perỉodo, obtēm-se uma perfeita correlação entre desmatamento e expansão das āreas de lavoura. A diferença de $0,65 \%$ pode ser atribuïda à expansão da lavoura em ăreas de campo ou à aglutinação de pequenas unidades coloniais.

Em sintese, esses valores poderão não ser significativos, mas indicam um processo que se desencadeou, num primeiro momento, pe la implantação das colónias agrícolas em āreas de mata, e num segun do momento, devido à política de incentivo agrícola, que favoreceu, por um lado, a expansão da lavoura nas āreas originalmente de mata, e por outro, a expansão das lavouras em āreas tipicamente de pasto reio. Fato que favoreceu, a expansão horizontal da agricultura, con tribuindo, como demonstram os dados aqui trabalhados, particularmen te no Rebordo do Planalto, ao aumento de ärea cultivada, em detrimen to das āreas de cobertura vegetal de grande porte.

CONSIDERAÇOES FINAIS

Os dados referidos neste trabaiho permitem avaliaros indi ces de desmatamento na bacia do rio Toropi, e, ao mesmo tempo, os in dices de expansão das äreas de lavoura. Em sintese, è a seguinte a situação da bacia neste aspecto:

predomina na bacia do rio Toropi, a vegetaçăc de campo. A Mata Subtropical Subcaduciföira, que constitui a vegetação original do Rebordo do Planălto, em 1964, jä se encontrava grandemente devas tada, e durante os doze anos estudados, sofreu um decréscimo em tor no de $25,51 \%$;

outras categorias analisadas como capões (em zona de cam po) e äreas de reflorestamento (eucalipto), também apresentaram de créscimo de āreas, tendo sido este, em valores relativos, de 56,03\% e $35,62 \%$ respectivamente; 
as āreas de campo do planalto, utilizadas inicialmente pa ra pastagem, da mesma forma que as demais categorias, sofreram um de créscimo. Em 1964, 86,50\% da bacia era constituída de campo; em 1975 este valor é de $84,72 \%$. Esta diminuição se explica pela significati va expansão das āreas de lavoura na região planaltina, que de 1964 a 1975 foi de $60,6 \%$ da ärea cultivada em 1964;

as äreas agrícolas, por sua vez, apresentaram nesses doze anos estudados, acréscimos significativos. Considerando o aumento de 1975 sobre o total da área cultivada em 1964, os valores encontrados foram de $73,75 \%$. Analisando os diferentes compartimentos do relevo, o que se verificou, foi o predomínio das äreas de lavoura no Rebor do do Planalto e na Depressão Central, correspondendo a $63,32 \%$ da ä rea cultivada na bacia em 1975, contra $36,68 \%$ de äreas de cultivo en contradas no setor do planalto para o mesmo ano.

Isto posto, conclui-se que os compartimentos da bacia do rio Toropi, mais significativos em termos de atividade agrícola,são a Depressão Central e principalmente o Rebordo do Planalto, que te ve ao longo do processo de ocupação de suas āreas uma contīnua subs tituição da vegetação original (Mata subtropical) pelas āreas de la voura, desenvolvidas em pequenas unidades de produção, sob o signo da policultura.

Em outras palavras, constitui esse compartimento um setor que merece estudos detalhados no que se refere ao desmatamento e os conseqüentes processos de degradação do solo, pois alēm de constituir a ärea de maior declividade e de maior umidade, sofre um processo ace lerado de desmatamento, aliado à utilização intensiva do solo. Inten sificação esta resultante, por um lado, da pequena extensão da pro priedade, por outro, da necessidade de explorä-la em sua quase tota lidade.

Em sintese, o desmatamento pela expansão das áreas de cul tivo na bacia do rio Toropi, reflete uma das características da agri cultura brasileira, ou seja, aumento da produção por expansão hor zontal.

Este fenōmeno acarreta, além de problemas sociais, a inten sificação da morfogênese e a conseqüente degradação do meio.

\section{AGRADECIMENTOS}

Aos professores Anilda Back da Silva, Maria Aparecida de Araüjo Mariano da Rocha e José Sales Mariano da Rocha, pelas suges toes apresentadas. Ao senhor Arthur Hector Cunha, pelo desenho das figuras.

BIBLIOGRAFIA

1. PRANDINI.F.L. et alii. Atuação da Cobertura Vegetal na Estabili 
dade das Encostas. Uma Resenha Crïtica. Instituto de Pesquisas Tecnológicas, São Paulo. II Congresso Brasileiro de Florestas Tropicais. Mossorō, RN. Publicação nọ 1074, 1976, p. 13.

2. KRUROWSKi,g. Aspectos Geogrāficos da Erosão no Norte do Paranā. Boletim Paranaense de Geografia, Curitiba, nọ 617, 1962 p.4 e 5 .

3. TRICART,J. La Epidermis de la Tierra. Nueva Colección labor, Bar celona, Espanha, 1969. p. 93.

4. LA SALVIA,F. Identificação das Formas de Uso da Terra e Cobertú ra Vegetal do Rio Grande do Sul Atravēs de Fotografias Aéreas. Boletim Geográfico do Rio Grande do Sul. Secretaria da Agricul tura, CEMAPA, Unidade de Geografia e Cartografia, ano 18 (16): $125-154,1973$.

Recebido em outubro, 1980; aceito em dezembro, 1980. 


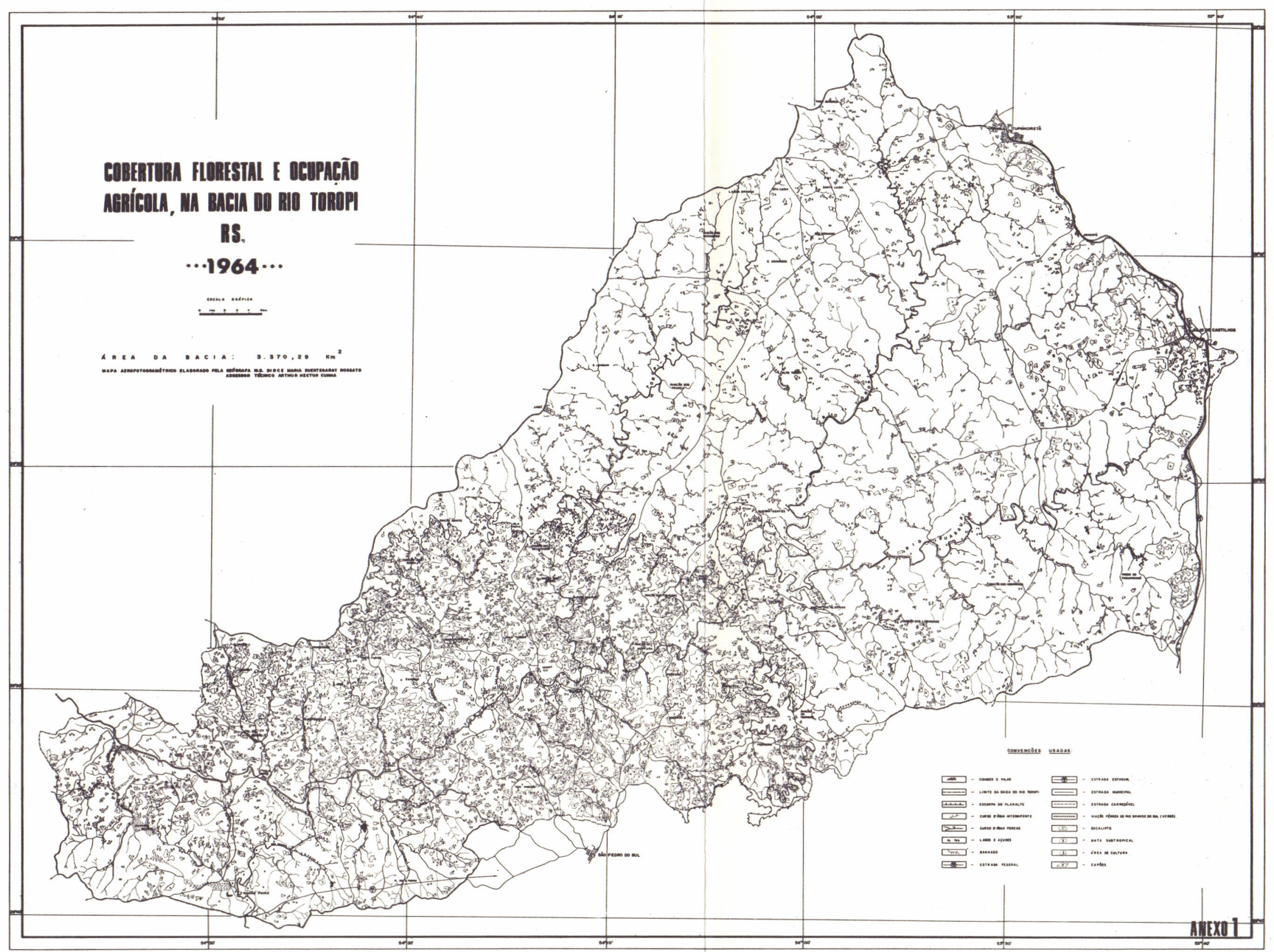




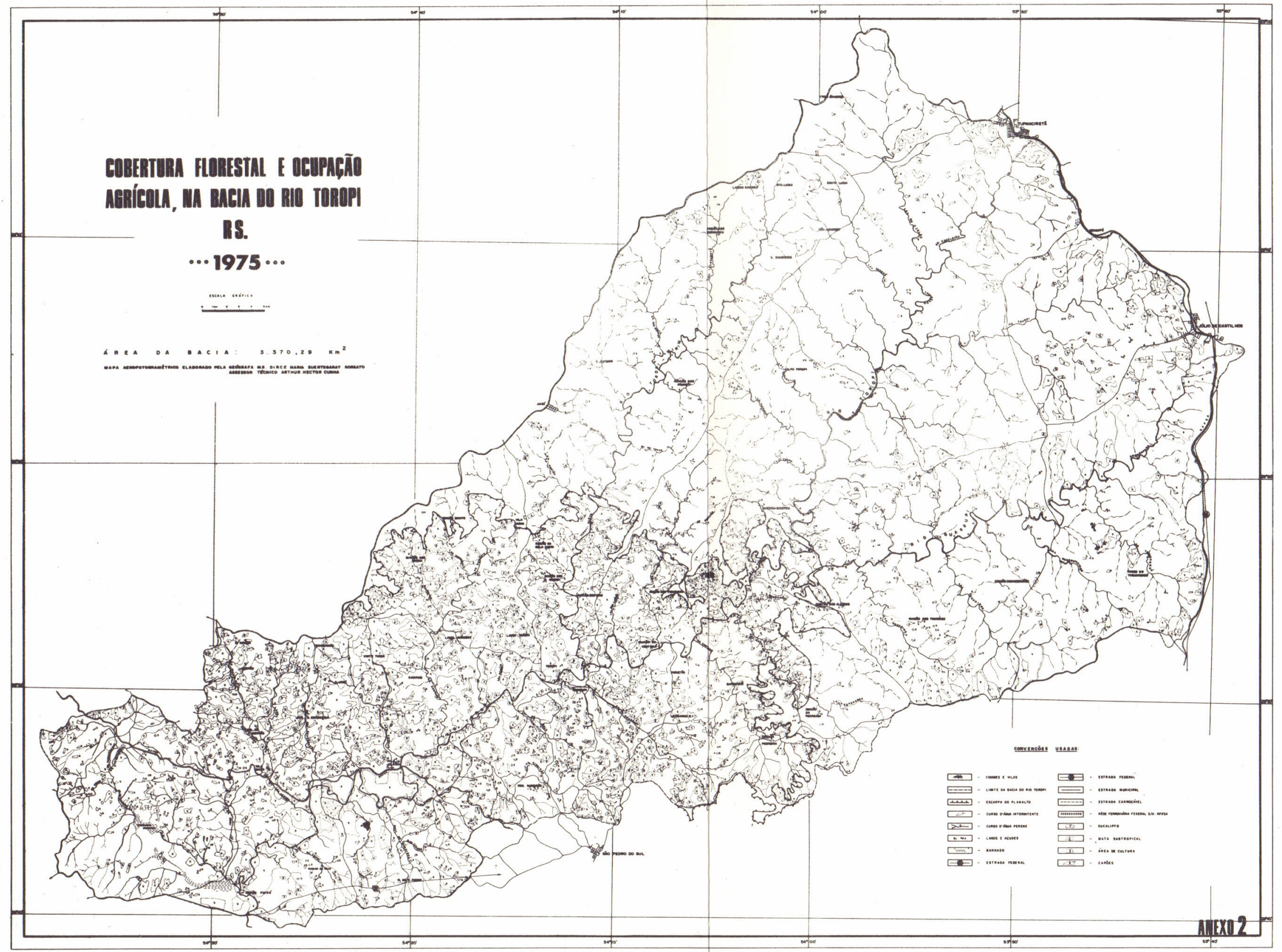




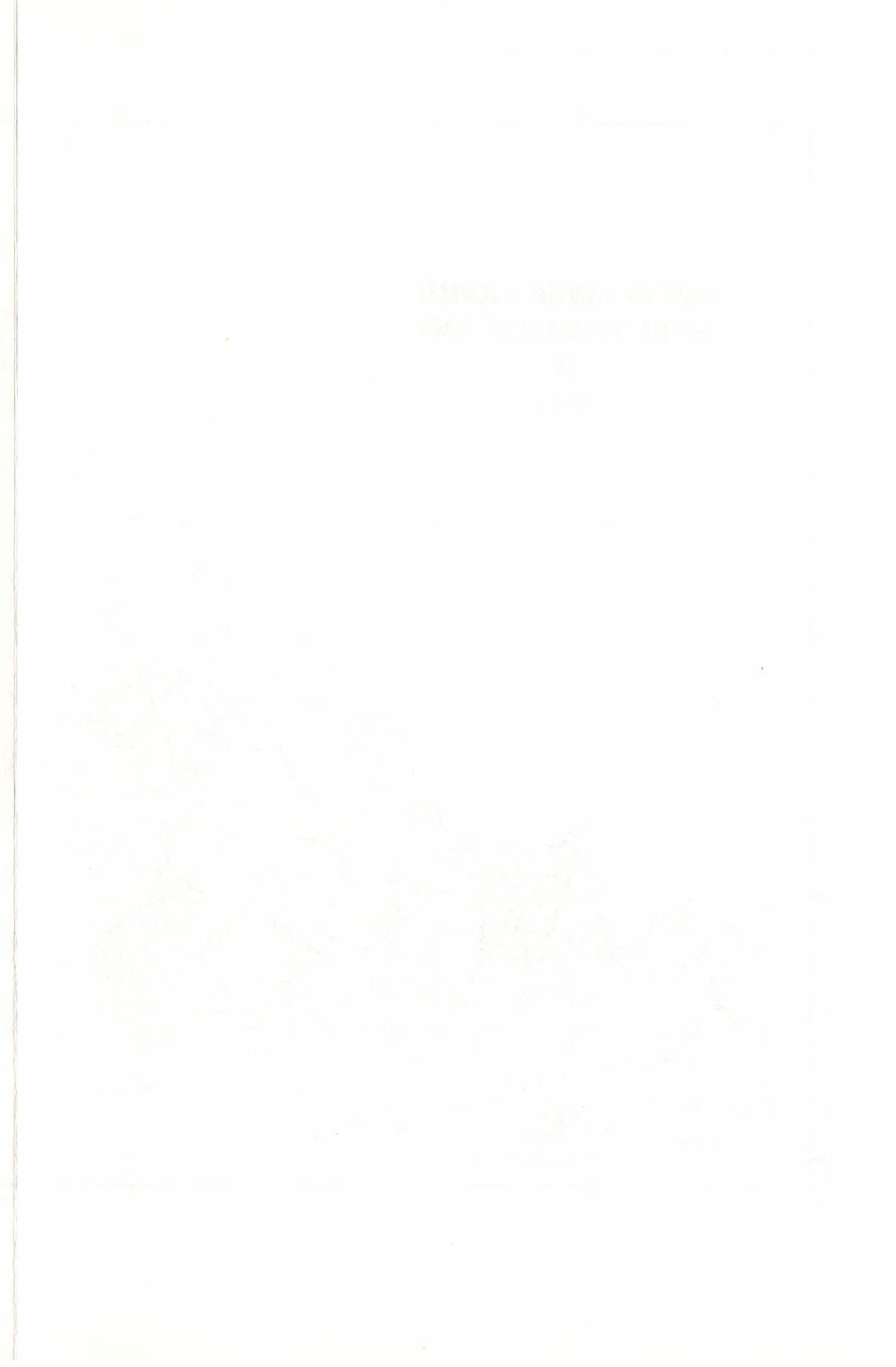

